\title{
Enhancement of saquinavir absorption and accumulation through the formation of solid drug nanoparticles
}

\author{
Gabriel Kigen ${ }^{1,2^{*}}$ iD and Geoffrey Edwards ${ }^{2}$
}

\begin{abstract}
Background: Nanotechnology is now considered a promising drug delivery method for orally administered hydrophobic drugs to their sites of action. The effect of nanodispersion on cellular transport and accumulation of saquinavir (SQV) was investigated.

Methods: The transport of five solid drug nanoparticle (SDN) SQV formulations along Caco-2 cell monolayers (CCM) was compared to that of standard SQV. The SDNs were prepared using SQV mesylate (20\%), Pluronic F127 (10\%) plus five other excipients (HPMC, PVP, PVA, Lecithin S75 and Span 80) in different proportions. Cellular accumulation in CEM parental and CEMVBL (P-gp overexpressing) cells was conducted to ascertain the effect of nanodispersion on P-gp mediated efflux of SQV. All SDN formulations were dissolved in water, whereas SQV in DMSO to improve solubility. Quantification was via HPLC.

Results: From transport results, an SDN sample composed of SQV mesylate/Pluronic F127 plus HPMC (70\%) and had a 24\% increase in apparent absorption compared to standard SQV, largely driven by a 38\% reduction in basolateral to apical permeation. Additionally, the formulation and two others (SQV mesylate/Pluronic F127 alone; and + HPMC (65\%)/Lecithin [5\%]) accumulated more significantly in CEM cells, suggesting enhanced delivery to these cells. Moreover, accumulation and transport of the three SDNs compared well to that of SQV despite being dissolved in water, suggestive of improved dissolution. The inclusion of PVA resulted in increased efflux.

Conclusion: The use of HPMC and Pluronic F127 produced SQV SDNs with improved permeation in Caco-2 cells and improved accumulation in CEM cells, but negative effects with PVA.
\end{abstract}

Keywords: Saquinavir, nanodispersion, solid drug nanoparticles, Caco-2 cell monolayers, transport, accumulation

\section{Background}

Despite success of highly active antiretroviral therapy (HAART) in the management of HIV/AIDS, there are still several challenges including ability of the drugs to cross physiological barriers in order to reach HIV cellular reservoirs in sufficient quantities [1]. Although current therapy is able to lower the viral load below detectable limits. HIV virus continues to survive in anatomical areas with poor drug permeation (sanctuary sites) such as CD4+ macrophages leading to increased likelihood of development of resistance $[1,2]$. Maximal

\footnotetext{
* Correspondence: kigengfk@gmail.com

'Department of Pharmacology and Toxicology, Moi University School of Medicine, P.O. Box 4606, Eldoret 30100, Kenya

${ }^{2}$ Department of Molecular and Clinical Pharmacology, University of Liverpool, Liverpool L69 3GE, UK
}

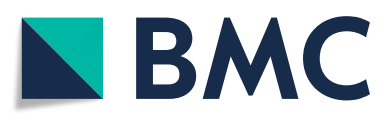

(c) The Author(s). 2018 Open Access This article is distributed under the terms of the Creative Commons Attribution 4.0 International License (http://creativecommons.org/licenses/by/4.0/), which permits unrestricted use, distribution, and reproduction in any medium, provided you give appropriate credit to the original author(s) and the source, provide a link to the Creative Commons license, and indicate if changes were made. The Creative Commons Public Domain Dedication waiver (http://creativecommons.org/publicdomain/zero/1.0/) applies to the data made available in this article, unless otherwise stated. equately penetrate these reservoir sites, and nanotechnology is now considered as a potential drug delivery system [3]. The system has several advantages including increased solubility, improved delivery, bioavailability and simultaneous delivery of two or more drugs $[4,5]$. It has also been demonstrated to circumvent the transporter mediated drug efflux, thus allowing the drugs to gain entry into cells $[6,7]$. The potential for nanoparticles to deliver drugs to the CNS with minimal adverse effects has also been reported $[8,9]$.

Currently, there are two main nanotechnology techniques that are utilized in the improvement of physical properties of hydrophobic drugs with a view to enhancing their solubility $[10,11]$. The first involves attachment or 
encapsulation of the drug to a vehicle (nano-carrier) such as polymeric materials and devices of nanometric size range [12]. Examples include liposomes, dendrimers, micelles and nanoemulsions [13, 14]. Drugs may also be linked to inorganic particles such as silica, iron, silver or gold [15]. The second involves manipulation of the drug to a particle dispersion (nanodispersion) which is then stabilized by a polymer and/or excipient to form solid drug nanoparticles (SDNs) [16]. Various polymer combinations and surfactants are used as excipients. Examples of the polymer combinations used include hydroxypropyl methylcellulose (HPMC), polyvinylpyrrolidone (PVP), polyvinyl alcohol (PVA), pluronic F68, pluronic F127, lecithin S75, Span 80 , hydrolysed gelatin, kallicoat protect and polyethylene glycol $1 \mathrm{k}$. The surfactants used include cremophor, solutol HS, Tween 20, Sisterna 16, hyamine, sodium alginate, and sodium caprylate [17]. The process involves the formation of oil-in-water emulsions (nanoemulsions) by dissolving hydrophobic drugs in a volatile water immiscible organic solvent and the water-soluble materials in water $[18,19]$. Dry powder composites (nanocrystals) are then formed through freeze-drying the emulsions in order to remove the volatile/aqueous phases [16]. The resultant product composed of the drug dispersed throughout the water-soluble material is a stable, dry and highly porous compound $[17,19]$. The method has been utilized to produce SDNs from several antiretroviral (ARV) drugs with better pharmacokinetic properties compared to the original drugs [16, 17, 20-22].

$\mathrm{SQV}$ is a potent ARV drug of the protease inhibitor (PI) class, but its use has been limited by its poor absorption with oral bioavailability of about 4\% [23-25]. SQV mesylate was the first PI to be approved for the treatment of HIV/AIDS but was discontinued after a year owing to development of resistance which was largely attributed to its poor bioavailability [26]. It was replaced by a soft gelatin formulation with improved bioavailability in 1997, which was however withdrawn in 2006 due to adverse effects and replaced by SQV boosted with RTV $[27,28]$. Like other PIs, SQV is a substrate of multidrug efflux transporters including P-gp which has been postulated to play a role in its therapeutic failures a result of reduced intracellular plasma concentrations due to increased flux [29-32]. For example, there is a 20 -fold increase in SQV plasma concentrations; upon co-administration with RTV a potent P-gp Inhibitor; hence its use in boosting the drug [33]. Several attempts have therefore been made to improve its absorption through design of formulations that can increase its bioavailability, including SDNs [34-38]. Nanotechnology has been demonstrated to enhance delivery and bioavailability of SQV through increased solubility, improved transport and evasion of the P-gp-mediated drug efflux [38-40]. Previous studies using the nanocarrier approach have demonstrated enhanced bioavailability of the drug, including disposition into the CNS [41-45].

The main objective of this research work was to investigate the effects of nanodispersion on the cellular transport and accumulation of SQV. The permeation of standard SQV along the CCM was compared with that of five SDNs of the drug prepared using various excipients as described earlier [39]. The SDNs were dissolved in distilled water, while standard SQV was dissolved in DMSO to improve solubility. The transport along the CCM of each SDN was compared to that of standard SQV using a method validated earlier in our laboratory [46]. In order to ascertain the effects of nanodispersion on the cellular accumulation of SQV, a P-glycoprotein [P-gp] substrate, the accumulation of the SDNs in CEM parental and CEMVBL cells (which overexpress P-gp) was compared to that of standard SQV using a method also developed earlier in our laboratory [47].

\section{Methods \\ Chemicals and reagents}

Caco- 2 cells were purchased from the European collection of cell cultures (ECACC No. 286010202), and the cells were counted using a Nucleo Counter (ChemoMetec, Lillerød, Denmark) cell counter. SQV was donated by Roche Pharmaceuticals (Welwyn Garden City, UK). The various SQV SDNs, were provided by IOTA NanoSolutions Ltd (MerseyBIO, Liverpool, UK). Clozapine (CLZ), Dulbecco's Modified Eagle Medium (DMEM), Roswell Park Memorial Institute medium (RPMI), Hanks' Balanced Salt solution (HBSS), Fetal bovine serum (FBS), Dimethyl sulfoxide (DMSO) and Trypsin-EDTA solution were purchased from Sigma Aldrich (Poole, UK). Acetonitrile $(\mathrm{ACN})$ and methanol $(\mathrm{MeOH})$ were purchased from VWR Laboratory Supplies (Poole, UK), whereas diethyl ether was purchased from Fisher Scientific (Loughborough, UK). All the other chemicals used were of analytical or HPLC grade. Deionized water used to prepare the solutions for mobile phase was purified in an Elga DV 25 pure lab option system (Egla, High Wycombe, Buckinghamshire, UK). T-lymphoblastoid cell lines, CEM and CEMVBL cells were gifts from Dr. R. Davey (University of Queensland, Brisbane, Australia).

\section{Equipment and chromatographic conditions}

The HPLC system consisted of a Dionex (Dionex Softron GmbH, Germering, Germany) HPLC system with a P 680 pump, an ASI-100 automated sample injector and a UVD 1704 detector. A $250 \mu \mathrm{l}$ injector with a $20 \mu \mathrm{l}$ loop was used. Reversed-phase-liquid chromatography was carried out using a HyPurity TM 22105-154630 C18 analytical column, $5 \mu \mathrm{m} \times 4.6 \mathrm{~mm} \times 150 \mathrm{~mm}$ (Thermo Electron Corporation, Runcorn, UK). A column guard (Thermo electron 60140-412) was used to protect the analytical column. The 
ultraviolet detector was set to monitor the 215-nm wavelength. The mobile phase for the analysis was composed of ammonium formate $20 \mathrm{mM}(\mathrm{pH}=4.2), \mathrm{ACN}$ and $\mathrm{MeOH}$ (57:38:5 v/v) and was prepared fresh for each assay. Separation was facilitated via isocratic elution at $1.5 \mathrm{ml} / \mathrm{min}$ flow rate and the run time was eight minutes for each separation. $20 \mu \mathrm{l}$ of the formulations was injected for each run by means of an automated injector. The peak area ratios for the calibration curves and quantification were obtained and analysed using Chromelon software (version 6.5). CLZ was used as internal standard. A Millicell Electrical Resistance System [ERS] (Fisher Scientific, Leicestershire, UK) was used for measuring the transepithelial electric resistance (TEER). Transwells (six-well transwell polycarbonate tissue culture treated plates, $4.67 \mathrm{~cm}^{2}, 24 \mathrm{~mm}$ diameter; $0.4 \mu \mathrm{m}$ pore size) were purchased from Corning life Sciences (Costar, High Wycombe, Buckinghamshire; UK).

\section{Cell culture}

The cells were cultured in DMEM and plated onto transwells at a density of $2 \times 10^{4}$ cells $/ \mathrm{cm}^{2}$ supplemented with $15 \%$ FBS; followed by incubation at $37{ }^{\circ} \mathrm{C}$ and $10 \% \mathrm{CO}_{2}$ in a humidified chamber with media change after every 2-3 days as described earlier [46-48]. Transport experiments were conducted 15 to 20 days after seeding and TEER across the cell monolayers was monitored until they were considered appropriate for the experiment (typically when the TEER values were above $500 \Omega$ ). The range of the range of TEERs used in our experiments were between 658 and $819 \Omega$.

\section{Cumulative trans-epithelial transport of SQV and the SDN formulations}

The compositions of the SQV SDNs (SQV O5, SQV O6, SQV O7, SQV O9 \& SQV 13) are as shown in Table 1. Solutions of $10 \mathrm{mg} / \mathrm{ml}$ standard SQV and the five SQV SDNs were prepared by weighing and dissolving in the appropriate solvent. SQV was dissolved in DMSO, while the SDNs in distilled water.

Each experiment was carried out using paired samples of standard SQV and an SQV SDN in order to maintain similar experimental conditions. TEER was measured prior to transport studies and each monolayer was washed using prewarmed HBSS and equilibrated with the transport medium (DMEM without FBS). The medium was aspirated from all apical (AP) and basolateral (BL) compartments of the transwells and replaced with $2 \mathrm{ml}$ of the transport medium (DMEM alone) and equilibrated for $1 \mathrm{hr}\left(37^{\circ} \mathrm{C}, 10 \% \mathrm{CO}_{2}\right.$ incubator), after which the TEER was re-assessed. The medium was then removed from both compartments and replaced with an equal volume of pre-warmed medium containing $20 \mu \mathrm{g} / \mathrm{ml}$ of the sample under investigation (SQV or SQV SDN). For the $\mathrm{AP} \rightarrow \mathrm{BL}$ transport, $2 \mathrm{ml}$ the medium containing the sample was placed on the apical chamber and $2 \mathrm{ml}$ of the medium alone on the basolateral chamber, whereas $2 \mathrm{ml}$ of medium containing the drug were placed on the basolateral and $2 \mathrm{ml}$ of medium on the apical chamber for the $\mathrm{BL} \rightarrow \mathrm{AP}$ transport. Transport in each direction was conducted in quintuplicate. The transwell plates were then incubated $\left(37{ }^{\circ} \mathrm{C}, 10 \% \mathrm{CO}_{2}\right.$ incubator) and $100 \mu \mathrm{l}$ was sampled hourly from the AP and BL compartments over 4 hr and replaced by freshly pre-warmed transport medium. The sampled were quantified via an HPLC method described earlier using a HyPurity $\mathrm{C}_{18}$ column and ultraviolet detection set at a wavelength of $215 \mathrm{~nm}$ [46]. The mobile phase consisted of ammonium formate, acetonitrile and methanol (57:38:5 v/v), and separation was facilitated via isocratic elution at a flow rate of $1.5 \mathrm{ml} / \mathrm{min}$ with clozapine as internal standard. The integrity of the CCM for each experiment was monitored by measuring the TEER at the beginning $(0 \mathrm{~min})$ and the end of the experiment $(240 \mathrm{~min})$. The transepithelial passage was assayed from the AP to the $\mathrm{BL}$ side and in the opposite direction $\mathrm{BL}$ to $\mathrm{AP}$ of the CCM. The results were expressed as apparent permeability $\left(P_{\mathrm{app}}\right.$, unit: $\left.\mathrm{cms}^{-1}\right)$, the amount of compound transported per second. Flux described the movement of a substance across the polarized Caco-2 monolayers either in absorptive $(\mathrm{AP} \rightarrow \mathrm{BL})$ or secretary direction $\left[\mathrm{BL} \rightarrow \mathrm{AP}\right.$ ] [48]. $P_{\text {app }}$ values were calculated for both AP to BL ( $\left.P_{\text {app AP-BL }}\right)$, and BL to AP ( $\left.P_{\text {appBL-AP }}\right)$ movement of the compound using the following equation:

$$
P_{\text {app }}(\mathrm{cm} / \mathrm{s})=\frac{(\mathrm{dQ} / \mathrm{dt})}{\left(1 /\left(\mathrm{AC}_{\mathrm{O}}\right)\right.}
$$

Where $\mathrm{dQ} / \mathrm{dt}$ is the steady-state flux $\left(\mu \mathrm{mol} \mathrm{s}{ }^{-1}\right)$, A the surface area of the filter $\left(\mathrm{cm}^{2}\right)$ and $\mathrm{C}_{\mathrm{O}}$ the initial

Table 1 Properties (chemical compositions and sizes) of the SQV SDNs

\begin{tabular}{|c|c|c|c|c|c|c|c|c|c|}
\hline Sample & \% SQV mesylate & $\%$ HPMC & $\%$ PVP & $\%$ PVA & \% Pluronic F 127 & \% Lecithin S 75 & \% Span 80 & Initial sample PS/nm & Type \\
\hline SQV 05 & 20 & 70 & & & 10 & & & 430 & \\
\hline SQV 06 & 20 & & & & 10 & & & 117 & M \\
\hline SQV 07 & 20 & & 70 & & 10 & & & 100 & M \\
\hline SQV 09 & 20 & 65 & & & 10 & 5 & & 196 & \\
\hline SQV 13 & 20 & & & 65 & 10 & & 5 & 336 & \\
\hline
\end{tabular}

HPMC Hydroxypropyl methyl cellulose, PVP Polyvinylpyrrolidone, PVA Polyvinyl alcohol, M Multimodal, PS Particle size 
concentration in the donor chamber $(\mu \mathrm{M})$. The equation applies only to the sink conditions, whereby the receiver concentration should not exceed $10 \%$ of the donor concentration and was therefore applied only for the samples taken at 60 minutes [48]. The apparent absorption was calculated using the formula: $\left(P_{\text {appAP-BL }} / P_{\text {appBL-AP }}\right)$.

\section{Cellular accumulation experiments}

CEM parental and CEMVBL cells were cultured in 175 $\mathrm{cm}^{2}$ flasks containing RPMI $(+10 \% \mathrm{FBS})$ in a humidified incubator $\left(37{ }^{\circ} \mathrm{C}, 10 \% \mathrm{CO}_{2}\right)$ as previously described [47]. The cells were counted and media containing 10 million cells centrifuged $\left(2000 \times g\right.$ for $5 \mathrm{~min}$ at $\left.4{ }^{\circ} \mathrm{C}\right)$ and the pellet reconstituted to a cell count of one million cells per $\mathrm{ml}$ in $10 \mathrm{ml}$ of fresh RPMI. This was followed by the addition of solutions of $100 \mu \mathrm{l}$ of $1 \mathrm{mg} / \mathrm{ml}$ of SQV and the SQV SDNs to yield a drug concentration of $10 \mu \mathrm{g} /$ $\mathrm{ml}$ in each flask. Each set of experiments consisted of seven flasks, one each for SQV and the five SQV SDNs. The seventh flask contained $100 \mu \mathrm{l}$ of $1 \mathrm{mg} / \mathrm{ml}$ of SQV combined with excipients used for the preparation of the SQV 13 sample. The purpose of carrying out this experiment was to rule out the possibility that the powder may have been responsible for the apparently reduced transport of sample 13 based on the results from Caco-2 experiment. The cells were then incubated at $37{ }^{\circ} \mathrm{C}$ for $30 \mathrm{~min}$ in a shaking water bath and the resulting cell suspensions centrifuged $\left(2000 \times g\right.$ for $5 \mathrm{~min}$ at $\left.4^{\circ} \mathrm{C}\right)$. Aliquots of $100 \mu \mathrm{l}$ of the supernatant fraction were then used to determine extracellular (EXT) concentration. The excess supernatant fraction was then removed and the resulting cell pellet washed three times in $10 \mathrm{ml}$ HBSS and then centrifuged $(2000 \times g$ for $5 \mathrm{~min})$. The resulting pellets were reconstituted in $100 \mu \mathrm{l}$ of distilled water and used to determine intracellular (INT) concentrations. The formulations were then assayed by HPLC and data expressed as cellular accumulation ratio (CAR) as described earlier [47].

\section{Statistical analysis}

Statistical analysis was performed using StatsDirect v.3 (UK). The results were presented as mean \pm standard deviation (SD) of five individual experiments with 95\% confidence intervals for differences between the means where appropriate. The assessment of normality was done using Shapiro-Wilk test and analysis performed using unpaired $t$-test as the data was found to be distributed normally. A two-tailed " $p$ value of $<0.05$ was accepted as being significant.

\section{Results}

\section{Cumulative trans-cellular transport}

The results for the apparent absorption are as outlined in Fig. 1 and Table 2. The SQV 05 SDN formulation had a $23.7 \%(0.69$ vs $0.90, p=0.61)$ increase in the apparent absorption compared to standard SQV after 1 hour of incubation. Two other SDN samples (SQV 06 \& 07) had a marginal decrease in the absorption compared to standard SQV, with that of SQV 13 being the most significant 0.69 at $71 \%(0.69$ vs $0.20, p=0.06)$ [Fig. 1]. It would therefore appear that the dissolution of these three samples improved, since they were dissolved in distilled water whereas standard SQV was dissolved in DMSO to increase solubility.

The apparent permeability coefficients are as shown in Fig. 2 and Table 3. The mean Papp ${ }_{B L-A P}$ transport was higher than the Papp ${ }_{\mathrm{AP}-\mathrm{BL}}$ across the spectrum as in the results from our previous study on SQV [46]. Additionally, the basolateral to apical permeation of SQV SDN 05 was higher than apical to basolateral permeation by $38 \%$ (8.9 vs 5.5) sample indicating that the increased apparent absorption was largely driven by a reduction in basolateral to apical permeation rather than by an enhancement in the apical to basolateral permeation (Fig. 2, Table 3).

\section{Accumulation experiments}

The intracellular accumulation results expressed as CAR are as shown in Fig. 3 and Tables 4. The intracellular accumulation of SQV in CEMVBL cells (which overexpress P-gp) was lower than CEM in all the formulations, suggesting that the formulations retained the P-gp substrate specificity as in our previous findings [47]. However, there was a significantly higher accumulation in CEM cells for three SDNs (SQV 05, 06 \& 09) compared to that of standard SQV; $1.52 \pm 0.19$ versus $1.94 \pm 0.16, p=$ 0.003 (SQV 05), vs $1.9 \pm 0.29, p=0.04$ (SQV 06), and 1.87 $\pm 0.25, p=0.04$ (SQV 09) [Fig. 3, Table 4a]. These results suggest the possibility of enhanced delivery to these cells, despite the efflux. The excipients had no significant effect on the accumulation of SQV (Table 4a). Likewise, there was no significant difference in the accumulation of SQV and the SQV SDNs within the CEMVBL cells (Table 4b).

\section{Discussion}

The main aim of this study was to investigate the effect of nanodispersion on the permeation of SQV along the CCM, a measure of its absorption [48-51]. The transport of standard SQV was compared with that of five SQV SDNs. Cellular accumulation in CEM and CEMVBL cells was performed in order to ascertain the effect on nanodispersion on the P-gp mediated efflux of the drug. CCM are well suited for the evaluation of drug transport since they have similar morphological and functional properties to intestinal enterocytes. The permeability of drugs through CCM therefore correlates well with in vivo absorption in humans [50, 51]. In addition, they express a wide array of drug transporters (both efflux and influx) as well as metabolic enzymes, 


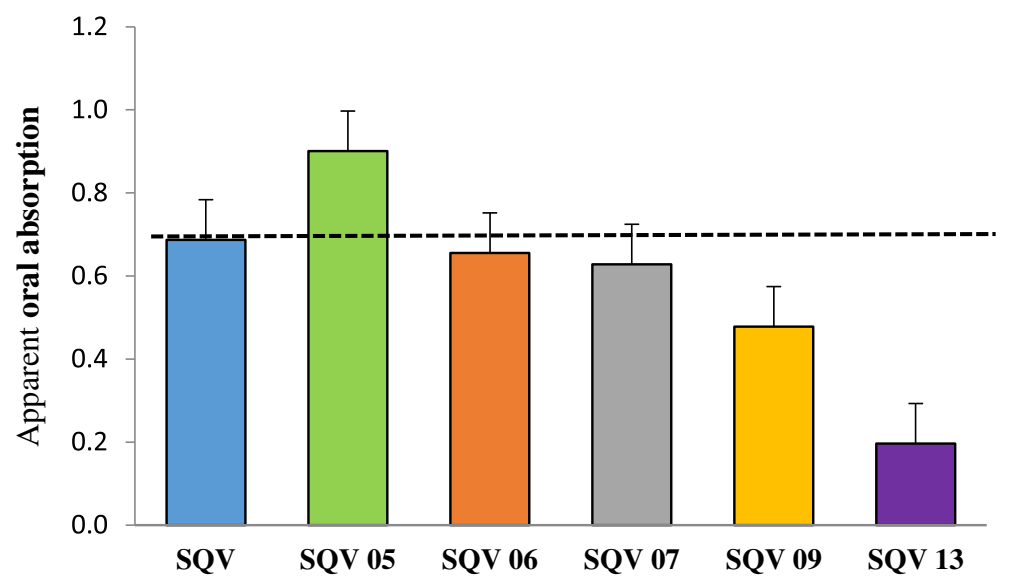

Fig. 1 Apparent absorption of standard SQV and five SQV SDNs across the differentiated Caco-2 monolayers after 1 hour of incubation ( $n=5$ )

thus making them suitable for in vitro drug transport studies [50, 52, 53].

From our transport results, one SDN sample (SQV 05) showed a $24 \%$ improvement in apparent absorption compared to standard SQV. This was demonstrated to be largely driven by a reduction in basolateral to apical permeation since its basolateral to apical permeation was lower than the apical to basolateral by $38 \%$. Intracellular accumulation indicated that SDN samples SQV 05, $06 \& 09$ accumulated more significantly in CEM cells, suggesting the possibility of enhanced delivery to these cells, despite the efflux. Additionally, their transport and accumulation compared well to that of standard SQV despite the fact that they were dissolved in water and SQV on DMSO to enhance its dissolution. This was suggestive of an improved dissolution. The excipients had no significant effect on the accumulation of SQV. These results suggest that SQV can potentially be manipulated to produce SDNs with improved absorption and accumulation by the use of suitable excipients. All the samples were composed of SQV mesylate (20\%) and Pluronic F127 (10\%), with SQV 06 having no extra excipient. SQV SDN 05 was composed of SQV mesylate (20\%), HPMC (70\%) and Pluronic F127 (10\%). The use Polyvinyl alcohol (PVA) polymer and Span 80 (surfactant) however, produced an SDN (SQV 13) with a reduced transport (increased efflux), an undesired effect. The reduction in $\mathrm{BL} \rightarrow \mathrm{AP}$ permeability demonstrated by the SQV 05 sample may have resulted from several mechanisms including endocytosis of the intact drug, increased paracellular permeability or indirect mechanisms that enable enhanced permeation of the dissolved drug [54-56]. It may have also been due to a reduction in the a P-gp mediated efflux transport $[29,57]$. SQV is a substrate of the multidrug efflux transporter P-gp, and its low oral bioavailability has been partly thought to be associated with the transporter [29, 32, 57, 58]. Previous studies have demonstrated increased in vivo bioavailability of SQV upon co-administration with of P-gp inhibitors [59]. It is noteworthy that the SQV SDNs were dissolved in water, whereas standard SQV was dissolved in DMSO in order to improve its solubility [39, 60-63]. This is an important observation as it means that the SDNs have potentially better dissolution than standard

Table 2 Comparison of the apparent absorptions of five SQV SDNs to that of standard SQV across differentiated Caco-2 monolayers after 1 hour of incubation ( $n=5)$

\begin{tabular}{lllllll}
\hline Sample & \multicolumn{4}{l}{ Apparent absorption $=$ Papp $_{\text {AP-BL }}$ / Papp } \\
\cline { 2 - 7 } & SQV & SQV SDN 05 & SQV SDN 06 & SQV SDN 07 & SQV SDN 09 & SQV SDN 13 \\
\hline 1 & 0.5 & 1.8 & 0.4 & 0.3 & 0.6 & 0.1 \\
2 & 0.2 & 0.2 & 0.4 & 0.1 & 0.2 & 0.3 \\
3 \\
4
\end{tabular}




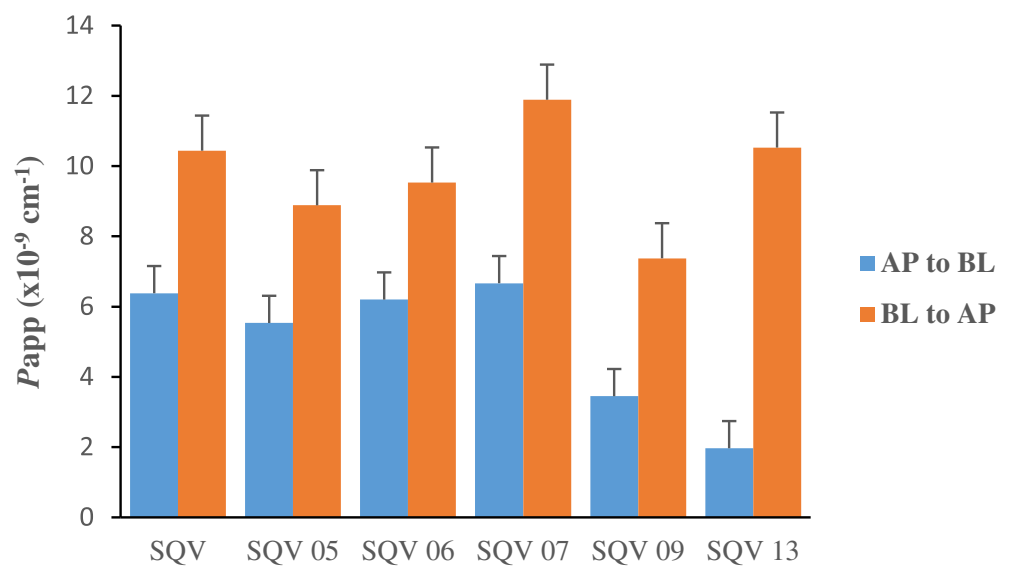

Fig. 2 Apparent permeability of standard SQV and five SQV SDNs across the differentiated Caco-2 monolayers after 1 hour of incubation ( $n=5$ )

SQV, which has been a major drawback in its absorption [23-25, 64]. Increased dissolution/solubility would potentially improve the bioavailability of the drug, controlling for the efflux [5, 24, 65-67]. From the cellular accumulation results, intracellular accumulation was lower in CEMVBL than in CEM parental cells for all SDNs including the standard drug as in our previous results [47]. Nanodispersion did not therefore appear to significantly affect accumulation in CEMVBL cells in SDNs, suggesting that it did not significantly affect the P-gp mediated efflux transport. CEMVBL cells overexpress P-gp, and with SQV being its substrate, its net intracellular accumulation is reduced. Further in vitro assays may be conducted in order to corroborate this by the use of known P-gp inhibitors such as tariquidar or amiodarone [32, 47, 68, 69]. However, in CEM cells, three SDNs (SQV 05, 06 \& 09) accumulated more significantly. This would perhaps suggest that at physiologically relevant P-gp density, there is enhanced delivery to these cells possibly via other transporters or through other mechanisms such as paracellular permeation $[32,54,57]$. It may have also resulted from an increase in solubility [5, 65-67].

Several studies on the effects of the ingredients on the cellular accumulation and transport of nanoparticles (NPs) in various cell lines have reported a number of

Table 3 Comparison of the apparent permeabilities for the apical to basal and basolateral to apical transport of five SQV SDNs to that of standard SQV and across differentiated Caco-2 monolayers after 1 hour of incubation $(n=5)$

\begin{tabular}{|c|c|c|c|c|c|c|c|c|}
\hline \multicolumn{9}{|c|}{ a) Apical to basolateral } \\
\hline \multirow[b]{2}{*}{ Sample } & \multicolumn{8}{|c|}{$\operatorname{Papp}_{\mathrm{A}-\mathrm{B}}\left(\times 10^{-9} \mathrm{cms}^{-1}\right)$} \\
\hline & 1 & 2 & 3 & 4 & 5 & Mean & STDEV & $p$ value \\
\hline SQV & 3.6 & 2.7 & 2.4 & 15 & 8.0 & 6.4 & 5.4 & \\
\hline SQV SDN 05 & 3.2 & 3.1 & 5.1 & 6.2 & 10 & 5.5 & 2.9 & $p=0.77$ \\
\hline SQV SDN 06 & 1.9 & 4.1 & 8.7 & 3.1 & 13 & 6.2 & 4.7 & $p=0.96$ \\
\hline SQV SDN 07 & 2.0 & 2.0 & 5.1 & 14 & 10 & 6.7 & 5.3 & $p=0.94$ \\
\hline SQV SDN 09 & 1.8 & 1.4 & 3.4 & 3.4 & 7.2 & 3.4 & 2.3 & $p=0.30$ \\
\hline SQV SDN 13 & 0.7 & 2.1 & 0.6 & 0.3 & 6.2 & 2.0 & 2.5 & $p=0.06$ \\
\hline \multicolumn{9}{|c|}{ b) Basolateral to apical } \\
\hline & \multicolumn{8}{|c|}{$\operatorname{Papp}_{\mathrm{B}-\mathrm{A}}\left(\times 10^{-9} \mathrm{cms}^{-1}\right)$} \\
\hline Sample & 1 & 2 & 3 & 4 & 5 & Mean & STDEV & $p$ value \\
\hline SQV & 7.3 & 13 & 14 & 9.0 & 9.3 & 10 & 2.8 & \\
\hline SQV SDN 05 & 1.8 & 14 & 14 & 7.6 & 7.9 & 8.9 & 4.9 & $p=0.56$ \\
\hline SQV SDN 06 & 5.2 & 9.7 & 17 & 7.2 & 8.5 & 9.5 & 4.5 & $p=0.71$ \\
\hline SQV SDN 07 & 6.2 & 14 & 18 & 8.9 & 12 & 12 & 4.5 & $p=0.56$ \\
\hline SQV SDN 09 & 3.0 & 5.9 & 12 & 7.2 & 9.2 & 7.4 & 3.3 & $p=0.15$ \\
\hline SQV SDN 13 & 5.9 & 16 & 14 & 7.9 & 9.5 & 11 & 4.1 & $p=0.97$ \\
\hline
\end{tabular}




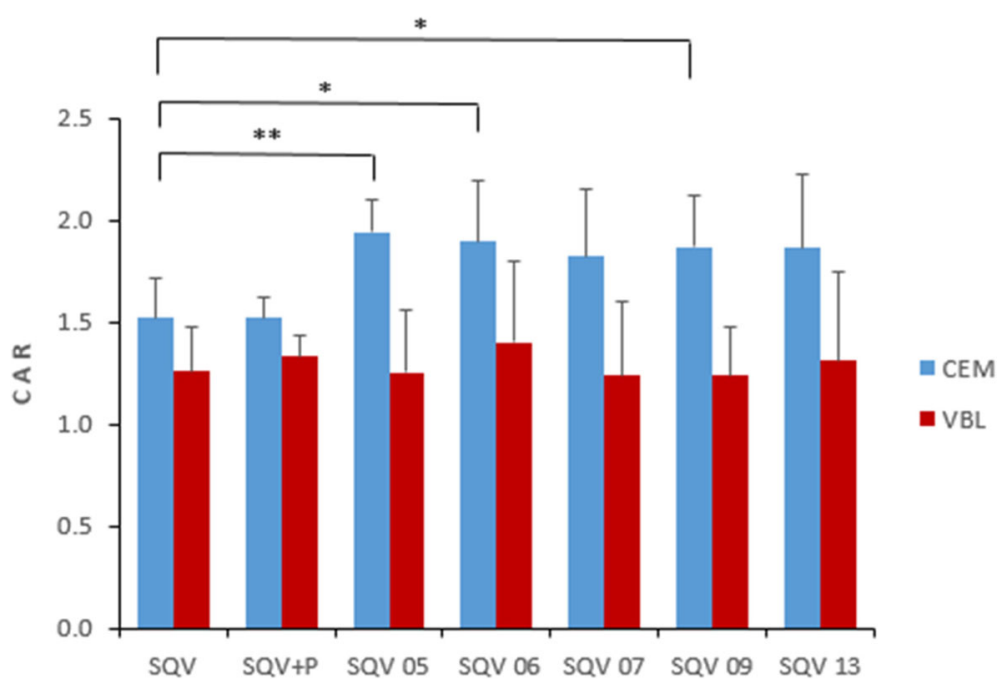

Fig. 3 Cellular accumulation ratios [CAR] (Mean $\pm S D, n=5), * p<0.05,{ }^{* *} p<0.01$

influencing factors. The type of polymer and surfactant used impacts on the pharmacokinetics of a NP by altering its properties including composition, size/diameter, shape and surface chemistry including charge (zeta potential) [70-72]. F127 and PVA have been associated with small particle size while carboxymethylcellulose $(\mathrm{Na}-\mathrm{CMC})$ has been linked to NPs with larger sizes which tend to be eliminated faster from the body [72]. Increased accumulation of SDNs CEM cells has also been shown to be influenced by an increase in diameter, whereas increased zeta potential had a positive influence on CAR in Caco-2 cells, but a negative influence in HepG2 cells. In addition, PVA, Tween 80 and F 127 had a negative effect on accumulation in CEM cells, while $\mathrm{F}$ 68 had a positive influence on the permeability in Caco-2 cells [17]. From our results, HPMC and Pluronic F 127 had positive influence on accumulation, whereas PVA had a negative influence.

Table 4 Intracellular accumulation of SQV, SQV combined with excipients for SQV 13 and the SQV SDNs in CEM and CEMVBL cells

\begin{tabular}{|c|c|c|c|c|c|c|c|c|}
\hline \multicolumn{9}{|l|}{ a) CEM cells } \\
\hline \multirow[b]{2}{*}{ Sample } & \multicolumn{8}{|c|}{ Cellular accumulation ration (CAR) } \\
\hline & 1 & 2 & 3 & 4 & 5 & Average & STDEV & $p$ value \\
\hline CEM SQV & 1.5 & 1.3 & 1.8 & 1.6 & 1.4 & 1.5 & 0.2 & \\
\hline CEM SQV+P & 1.5 & 1.6 & 1.5 & 1.7 & 1.4 & 1.5 & 0.1 & $p=0.97$ \\
\hline CEM SQV 05 & 2.2 & 1.8 & 1.8 & 1.9 & 2.0 & 1.9 & 0.2 & $p=0.03$ \\
\hline CEM SQV 06 & 2.2 & 1.5 & 2.1 & 2.0 & 1.7 & 1.9 & 0.3 & $p=0.04$ \\
\hline CEM SQV 07 & 2.1 & 1.4 & 1.8 & 2.2 & 1.6 & 1.8 & 0.3 & $p=0.12$ \\
\hline CEM SQV 09 & 1.9 & 1.6 & 1.9 & 2.3 & 1.7 & 1.9 & 0.3 & $p=0.04$ \\
\hline CEM SQV 13 & 1.8 & 1.6 & 1.5 & 2.1 & 2.4 & 1.9 & 0.4 & $p=0.10$ \\
\hline \multicolumn{9}{|c|}{ b) CEM VBL cells } \\
\hline & \multicolumn{8}{|c|}{ Cellular accumulation ration (CAR) } \\
\hline Sample & 1 & 2 & 3 & 4 & 5 & Average & STDEV & $p$ value \\
\hline VBL SQV & 1.0 & 1.1 & 1.3 & 1.4 & 1.5 & 1.3 & 0.2 & \\
\hline VBL SQV+P & 1.2 & 1.5 & 1.4 & 1.2 & 1.4 & 1.3 & 0.1 & $p=0.48$ \\
\hline VBL SQV 05 & 1.0 & 0.9 & 1.3 & 1.4 & 1.7 & 1.3 & 0.3 & $p=0.99$ \\
\hline VBL SQV 06 & 1.0 & 1.1 & 1.5 & 1.6 & 1.9 & 1.4 & 0.4 & $p=0.49$ \\
\hline VBL SQV 07 & 0.8 & 1.0 & 1.2 & 1.5 & 1.7 & 1.2 & 0.4 & $p=0.93$ \\
\hline VBL SQV 09 & 1.1 & 0.9 & 1.4 & 1.5 & 1.3 & 1.2 & 0.2 & $p=0.92$ \\
\hline VBL SQV 13 & 1.0 & 0.8 & 1.4 & 1.5 & 1.9 & 1.3 & 0.4 & $p=0.80$ \\
\hline
\end{tabular}

$\mathrm{P}=$ Excipients for SQV 13 sample 


\section{Conclusions}

The main finding from our study is that SQV can potentially be developed into SDNs with optimized pharmacological properties through nanodispersion. One SDN sample (SQV 05) showed a $24 \%$ improvement in the apparent absorption, which was largely driven by a by a $38 \%$ reduction in the basolateral to apical permeation. This sample was composed of SQV mesylate (20\%), HPMC (70\%) and Pluronic F127 (10\%). In addition, three SDN formulations (SQV 05, 06 \& 09) accumulated more significantly in CEM cells, suggesting that at physiologically relevant P-gp density, there is enhanced delivery to these cells possibly via other transporters, through increased solubility, or other mechanisms such as paracellular permeation. The transport and accumulation of these SQV SDNs also compared well to that of standard SQV despite being dissolved in water and SQV on DMSO to enhance solubility. This was suggestive of improved dissolution. However, the use Polyvinyl alcohol (PVA) and Span 80 produced an SDN (SQV 13) with increased efflux. Further research be may be conducted to ascertain in vivo effects.

\section{Abbreviations}

ACN: acetonitrile; AIDS: Acquired Immune Deficiency Syndrome; AP: apical; ARV: antiretroviral; BL: basolateral; CAR: cellular accumulation ratio; CCM: Caco-2 cell monolayers; CNS: central nervous system; CTAB: cetrimonium bromide; DMEM: Dulbecco's Modified Eagle Medium; DMSO: Dimethyl sulfoxide; DOSS: dioctyl sodium sulfosuccinate; ER: efflux ratio; EXT: extracellular; FBS: fetal bovine serum; HBSS: Hanks' Balanced Salt Solution; HIV: Human Immunodeficiency Virus; HPLC: High Pressure Liquid Chromatography; HPMC: hydroxypropyl methylcellulose; INT: intracellular; MeOH: methanol; NP: Nanoparticles; Papp: apparent permeability; P-gp: Pglycoprotein; Pl: Protease inhibitor; PVA: polyvinyl alcohol; PVP: polyvinylpyrrolidone; RPMI: Roswell Park Memorial Institute medium; RTV: ritonavir; SDNs: solid drug nanoparticles; SDS: sodium dodecyl sulphate; SQV: saquinavir; TEER: transepithelial resistance

\section{Acknowledgements}

The authors would like to thank the staff at the Department of Molecular and Clinical Pharmacology, University of Liverpool for their assistance in carrying out laboratory work.

\section{Funding}

No funding was obtained for this study.

\section{Availability of data and materials}

The datasets used and/or analysed during the current study available from the corresponding author on reasonable request.

\section{Authors' contributions}

GK and GE designed the study. GK carried out the HPLC assays. GK and GE extracted and analysed the data and wrote the manuscript. Both authors read and approved the final manuscript.

\section{Ethics approval and consent to participate}

Not applicable.

\section{Consent for publication}

Not applicable.

\section{Competing interests}

The authors declare that there are no competing interests.

\section{Publisher's Note}

Springer Nature remains neutral with regard to jurisdictional claims in published maps and institutional affiliations.

Received: 26 June 2018 Accepted: 26 November 2018

Published online: 04 December 2018

\section{References}

1. Fletcher CV, Staskus K, Wietgrefe SW, Rothenberger M, Reilly C, Chipman JG, Beilman GJ, Khoruts A, Thorkelson A, Schmidt TE, et al. Persistent HIV-1 replication is associated with lower antiretroviral drug concentrations in lymphatic tissues. Proceedings of the National Academy of Sciences of the United States of America. 2014:111:2307-12.

2. Kumar A, Abbas W, Herbein G. HIV-1 latency in monocytes/macrophages. Viruses. 2014;6:1837-60.

3. Curley P, Liptrott NJ, Owen A. Advances in nanomedicine drug delivery applications for HIV therapy. Future Science OA. 2017:FSO230.

4. Choi JY, Thapa RK, Yong CS, Kim JO. Nanoparticle-based combination drug delivery systems for synergistic cancer treatment. Journal of Pharmaceutical Investigation. 2016:46:325-39.

5. Dizaj SM, Vazifehasl Z, Salatin S, Adibkia K, Javadzadeh Y. Nanosizing of drugs: Effect on dissolution rate. Research in pharmaceutical sciences. 2015; 10:95-108.

6. Xue X, Liang XJ. Overcoming drug efflux-based multidrug resistance in cancer with nanotechnology. Chinese journal of cancer. 2012;31:100-9.

7. Mahajan SD, Aalinkeel R, Law W-C, Reynolds UL, Nair BB, Sykes DE, Yong K-T, Roy I, Prasad PN, Schwartz SA. Anti-HIV-1 nanotherapeutics: promises and challenges for the future. International journal of nanomedicine. 2012;7:5301-14.

8. Sagar V, Pilakka-Kanthikeel S, Pottathil R, Saxena SK, Nair M. Towards nanomedicines for neuro-AIDS. Reviews in medical virology. 2014;24:103-24.

9. Gomes MJ, Jd N, Sarmento B. Nanoparticle-based drug delivery to improve the efficacy of antiretroviral therapy in the central nervous system. International journal of nanomedicine. 2014;9:1757-69.

10. Xin Y, Huang Q, Tang JQ, Hou XY, Zhang P, Zhang LZ, Jiang G. Nanoscale drug delivery for targeted chemotherapy. Cancer letters. 2016;379:24-31.

11. Chang EH, Harford JB, Eaton MA, Boisseau PM, Dube A, Hayeshi R, Swai $H$, Lee DS. Nanomedicine: Past, present and future - A global perspective. Biochemical and biophysical research communications. 2015;468:511-7.

12. Moritz M, Geszke-Moritz M. Recent Developments in the Application of Polymeric Nanoparticles as Drug Carriers. Advances in clinical and experimental medicine: official organ Wroclaw Medical University. 2015; 24:749-58.

13. Din Fu AW, Ullah I, Qureshi OS, Mustapha O, Shafique S, Zeb A. Effective use of nanocarriers as drug delivery systems for the treatment of selected tumors. International journal of nanomedicine. 2017;12:7291-309.

14. Aboalnaja KO, Yaghmoor S, Kumosani TA, McClements DJ. Utilization of nanoemulsions to enhance bioactivity of pharmaceuticals, supplements, and nutraceuticals: Nanoemulsion delivery systems and nanoemulsion excipient systems. Expert opinion on drug delivery. 2016;13:1327-36.

15. Yoon HY, Jeon S, You DG, Park JH, Kwon IC, Koo H, Kim K. Inorganic Nanoparticles for Image-Guided Therapy. Bioconjugate chemistry. 2017; 28:124-34.

16. McDonald TO, Giardiello M, Martin P, Siccardi M, Liptrott NJ, Smith D, Roberts P, Curley P, Schipani A, Khoo SH, et al. Antiretroviral solid drug nanoparticles with enhanced oral bioavailability: production, characterization, and in vitro-in vivo correlation. Advanced healthcare materials. 2014;3:400-11.

17. Siccardi M, Martin P, Smith D, Curley P, McDonald T, Giardiello M, Liptrott N, Rannard S, Owen A. Towards a rational design of solid drug nanoparticles with optimised pharmacological properties. Journal of interdisciplinary nanomedicine. 2016;1:110-23.

18. Giardiello M, McDonald TO, Lee J-S, Roberts AD, Owen A, Rannard SP. Reactions of hydrophobic organic nanoparticle mixtures in water: nanoparticle-on-nanoparticle oxidative dye bleaching. Green Chemistry. 2013; 15:1590-9.

19. McDonald TO, Martin P, Patterson JP, Smith D, Giardiello M, Marcello M, See V, O'Reilly RK, Owen A, Rannard S. Multicomponent Organic Nanoparticles for Fluorescence Studies in Biological Systems. Advanced Functional Materials. 2012;22:2469-78.

20. Moss D, Siccardi M, Martin P, Smith D, Gurjar R, Rannard SP, Owen A, Town AR, Giardiello M, Gurjar R, et al. Dual-stimuli responsive injectable microgel/ 
solid drug nanoparticle nanocomposites for release of poorly soluble drugs. Nature communications. 2017:9:6302-14.

21. Giardiello M, Liptrott NJ, McDonald TO, Moss D, Siccardi M, Martin P, Smith D, Gurjar R, Rannard SP, Owen A. Accelerated oral nanomedicine discovery from miniaturized screening to clinical production exemplified by paediatric HIV nanotherapies. Nature communications. 2016;7:13184

22. Trezza C, Ford SL, Spreen W, Pan R, Piscitelli S. Formulation and pharmacology of long-acting cabotegravir. Current opinion in HIV and AIDS. 2015;10:239-45.

23. Buchanan CM, Buchanan NL, Edgar KJ, Little JL, Ramsey MG, Ruble KM, Wacher VJ, Wempe MF. Pharmacokinetics of saquinavir after intravenous and oral dosing of saquinavir: hydroxybutenyl-beta-cyclodextrin formulations. Biomacromolecules. 2008;9:305-13.

24. Mahajan HS, Pingale MH, Agrawal KM. Solubility and dissolution enhancement of saquinavir mesylate by inclusion complexation technique. Journal of Inclusion Phenomena and Macrocyclic Chemistry. 2013;76:467-72.

25. Sinko PJ, Kunta JR, Usansky HH, Perry BA. Differentiation of gut and hepatic first pass metabolism and secretion of saquinavir in ported rabbits. The Journal of pharmacology and experimental therapeutics. 2004;310:359-66.

26. Baker R. FDA approves $3 T C$ and saquinavir. Food and Drug Administration. BETA. 1995;5:9.

27. Kurowski M, Sternfeld T, Sawyer A, Hill A, Mocklinghoff C. Pharmacokinetic and tolerability profile of twice-daily saquinavir hard gelatin capsules and saquinavir soft gelatin capsules boosted with ritonavir in healthy volunteers. HIV Med. 2003:4:94-100.

28. Figgitt DP, Plosker GL. Saquinavir soft-gel capsule: an updated review of its use in the management of HIV infection. Drugs. 2000;60:481-516.

29. Konig SK, Herzog M, Theile D, Zembruski N, Haefeli WE, Weiss J. Impact of drug transporters on cellular resistance towards saquinavir and darunavir. The Journal of antimicrobial chemotherapy. 2010;65:2319-28.

30. Huang L, Wring SA, Woolley JL, Brouwer KR, Serabjit-Singh C, Polli JW. Induction of P-glycoprotein and cytochrome P450 3A by HIV protease inhibitors. Drug metabolism and disposition: the biological fate of chemicals. 2001;29:754-60.

31. Minuesa G, Huber-Ruano I, Pastor-Anglada M, Koepsell H, Clotet B, MartinezPicado J. Drug uptake transporters in antiretroviral therapy. Pharmacology \& therapeutics. 2011;132:268-79.

32. Janneh O, Owen A, Chandler B, Hartkoorn RC, Hart CA, Bray PG, Ward SA. Back DJ, Khoo SH: Modulation of the intracellular accumulation of saquinavir in peripheral blood mononuclear cells by inhibitors of MRP1, MRP2, P-gp and BCRP. AIDS (London, England). 2005;19:2097-102.

33. Veldkamp Al, van Heeswijk RP, Mulder JW, Meenhorst PL, Schreij G, van der Geest S, Lange JM, Beijnen JH, Hoetelmans RM. Steady-state pharmacokinetics of twice-daily dosing of saquinavir plus ritonavir in HIV-1infected individuals. Journal of acquired immune deficiency syndromes (1999). 2001;27:344-9.

34. Luo S, Wang Z, Patel M, Khurana V, Zhu X, Pal D, Mitra AK. Targeting SVCT for enhanced drug absorption: synthesis and in vitro evaluation of a novel vitamin C conjugated prodrug of saquinavir. International journal of pharmaceutics. 2011;414:77-85.

35. Wang Z, Pal D, Mitra AK. Stereoselective evasion of P-glycoprotein, cytochrome P450 3A, and hydrolases by peptide prodrug modification of saquinavir. Journal of pharmaceutical sciences. 2012;101:3199-213.

36. Pathak SM, Musmade P, Dengle S, Karthik A, Bhat K, Udupa N. Enhanced oral absorption of saquinavir with Methyl-Beta-Cyclodextrin-Preparation and in vitro and in vivo evaluation. European journal of pharmaceutical sciences: official journal of the European Federation for Pharmaceutical Sciences. 2010;41:440-51.

37. He Y, D-n X, Li Q-X, J-s T, Gan Y, Wang C. Enhancement of cellular uptake, transport and oral absorption of protease inhibitor saquinavir by nanocrystal formulation. Acta pharmacologica Sinica. 2015;36:1151-60.

38. Dodiya SS, Chavhan SS, Sawant KK, Korde AG. Solid lipid nanoparticles and nanosuspension formulation of Saquinavir: preparation, characterization, pharmacokinetics and biodistribution studies. Journal of microencapsulation. 2011:28:515-27.

39. He Y, Xia DN, Li QX, Tao JS, Gan Y, Wang C. Enhancement of cellular uptake, transport and oral absorption of protease inhibitor saquinavir by nanocrystal formulation. Acta pharmacologica Sinica. 2015;36:1151-60.

40. Beloqui A, Solinis MA, Gascon AR, del Pozo-Rodriguez A, des Rieux A, Preat $V$. Mechanism of transport of saquinavir-loaded nanostructured lipid carriers across the intestinal barrier. Journal of controlled release : official journal of the Controlled Release Society. 2013;166:115-23.
41. Vyas TK, Shahiwala A, Amiji MM. Improved oral bioavailability and brain transport of Saquinavir upon administration in novel nanoemulsion formulations. International journal of pharmaceutics. 2008;347:93-101.

42. Kuo YC, Yu HW. Transport of saquinavir across human brain-microvascular endothelial cells by poly(lactide-co-glycolide) nanoparticles with surface poly-(gamma-glutamic acid). International journal of pharmaceutics. 2011; 416:365-75.

43. Mahajan HS, Mahajan MS, Nerkar PP, Agrawal A. Nanoemulsion-based intranasal drug delivery system of saquinavir mesylate for brain targeting. Drug delivery. 2014;21:148-54

44. Al-Kassas R, Bansal M, Shaw J. Nanosizing techniques for improving bioavailability of drugs. Journal of controlled release : official journal of the Controlled Release Society. 2017;260:202-12.

45. Lai F, Schlich M, Pireddu R, Corrias F, Fadda AM, Sinico C. Production of nanosuspensions as a tool to improve drug bioavailability: focus on topical delivery. Current pharmaceutical design. 2015;21:6089-103.

46. Kigen G, Edwards G. Drug-transporter mediated interactions between anthelminthic and antiretroviral drugs across the Caco-2 cell monolayers. BMC pharmacology \& toxicology. 2017;18:20.

47. Kigen $\mathrm{G}$, Edwards $\mathrm{G}$. Intracellular accumulation of Praziquantel in $T$ lymphoblastoid cell lines, CEM (parental) and CEMVBL(P-gp-overexpressing). BMC pharmacology \& toxicology. 2016;17:37.

48. Hubatsch I, Ragnarsson EG, Artursson P. Determination of drug permeability and prediction of drug absorption in Caco-2 monolayers. Nature protocols. 2007;2:2111-9.

49. Milanetti E, Raimondo D, Tramontano A. Prediction of the permeability of neutral drugs inferred from their solvation properties. Bioinformatics. 2016; 32:1163-9.

50. Press B. Optimization of the Caco-2 permeability assay to screen drug compounds for intestinal absorption and efflux. Methods in molecular biology (Clifton, NJ). 2011;763:139-54.

51. van Breemen RB, Li Y. Caco-2 cell permeability assays to measure drug absorption. Expert opinion on drug metabolism \& toxicology. 2005;1:175-85.

52. Elsby R, Surry DD, Smith VN, Gray AJ. Validation and application of Caco-2 assays for the in vitro evaluation of development candidate drugs as substrates or inhibitors of P-glycoprotein to support regulatory submissions. Xenobiotica; the fate of foreign compounds in biological systems. 2008;38: $1140-64$.

53. Press B, Di Grandi D. Permeability for intestinal absorption: Caco-2 assay and related issues. Current drug metabolism. 2008:9:893-900.

54. Tatham LM, Rannard SP, Owen A. Nanoformulation strategies for the enhanced oral bioavailability of antiretroviral therapeutics. Therapeutic delivery. 2015;6:469-90.

55. Shahbazi MA, Santos HA. Improving oral absorption via drug-loaded nanocarriers: absorption mechanisms, intestinal models and rational fabrication. Current drug metabolism. 2013;14:28-56.

56. Yameen B, Choi WI, Vilos C, Swami A, Shi J, Farokhzad OC. Insight into nanoparticle cellular uptake and intracellular targeting. Journal of controlled release : official journal of the Controlled Release Society. 2014:190:485-99.

57. Usansky HH, Hu P, Sinko PJ. Differential roles of P-glycoprotein, multidrug resistance-associated protein 2, and CYP3A on saquinavir oral absorption in Sprague-Dawley rats. Drug metabolism and disposition: the biological fate of chemicals. 2008;36:863-9.

58. Maffeo A, Bellomi F, Solimeo I, Bambacioni F, Scagnolari C, De Pisa F, Dupuis ML, Cianfriglia M, Antonelli G, Turriziani O. P-glycoprotein expression affects the intracellular concentration and antiviral activity of the protease inhibitor saquinavir in a T cell line. The new microbiologica. 2004;27:119-26.

59. Martin-Facklam M, Burhenne J, Ding R, Fricker R, Mikus G, Walter-Sack I, Haefeli WE. Dose-dependent increase of saquinavir bioavailability by the pharmaceutic aid cremophor EL. British Journal of Clinical Pharmacology. 2002;53:576-81.

60. Yeh M-K, Chang L-C, Chiou AH-J. Improving Tenoxicam Solubility and Bioavailability by Cosolvent System. AAPS PharmSciTech. 2009;10:166-71.

61. Papaneophytou CP, Mettou AK, Rinotas V, Douni E, Kontopidis GA. Solvent Selection for Insoluble Ligands, a Challenge for Biological Assay Development: A TNF-a/SPD304 Study. ACS Medicinal Chemistry Letters. 2013; 4:137-41.

62. Kerns EH, Di L, Carter GT. In vitro solubility assays in drug discovery. Current drug metabolism. 2008;9:879-85.

63. van Kampen JJ, Burgers PC, de Groot R, Osterhaus AD, Reedijk ML, Verschuren EJ, Gruters RA, Luider TM. Quantitative analysis of HIV-1 protease 
inhibitors in cell lysates using MALDI-FTICR mass spectrometry. Analytical chemistry. 2008;80:3751-6.

64. Tam-Zaman N, Tam YK, Tawfik S, Wiltshire H. Factors responsible for the variability of saquinavir absorption: studies using an instrumented dog model. Pharmaceutical research. 2004;21:436-42.

65. Khames A. Investigation of the effect of solubility increase at the main absorption site on bioavailability of BCS class II drug (risperidone) using liquisolid technique. Drug delivery. 2017;24:328-38.

66. Dahan A, Miller JM. The Solubility-Permeability Interplay and Its Implications in Formulation Design and Development for Poorly Soluble Drugs. The AAPS Journal. 2012;14:244-51.

67. Murtaza G. Solubility enhancement of simvastatin: a review. Acta poloniae pharmaceutica. 2012;69:581-90

68. Srinivas RV, Middlemas D, Flynn P, Fridland A. Human immunodeficiency virus protease inhibitors serve as substrates for multidrug transporter proteins MDR1 and MRP1 but retain antiviral efficacy in cell lines expressing these transporters. Antimicrob Agents Chemother. 1998:42:3157-62

69. Tiberghien F, Loor F. Ranking of P-glycoprotein substrates and inhibitors by a calcein-AM fluorometry screening assay. Anti-cancer drugs. 1996;7:568-78.

70. Moss DM, Siccardi M. Optimizing nanomedicine pharmacokinetics using physiologically based pharmacokinetics modelling. British journal of pharmacology. 2014;171:3963-79.

71. Kaminskas LM, Boyd BJ, Porter CJ. Dendrimer pharmacokinetics: the effect of size, structure and surface characteristics on ADME properties. Nanomedicine (London, England). 2011;6:1063-84.

72. Cho WS, Cho M, Jeong J, Choi M, Han BS, Shin HS, Hong J, Chung BH Jeong J, Cho MH. Size-dependent tissue kinetics of PEG-coated gold nanoparticles. Toxicology and applied pharmacology. 2010;245:116-23.

Ready to submit your research? Choose BMC and benefit from:

- fast, convenient online submission

- thorough peer review by experienced researchers in your field

- rapid publication on acceptance

- support for research data, including large and complex data types

- gold Open Access which fosters wider collaboration and increased citations

- maximum visibility for your research: over $100 \mathrm{M}$ website views per year

At $\mathrm{BMC}$, research is always in progress.

Learn more biomedcentral.com/submissions 